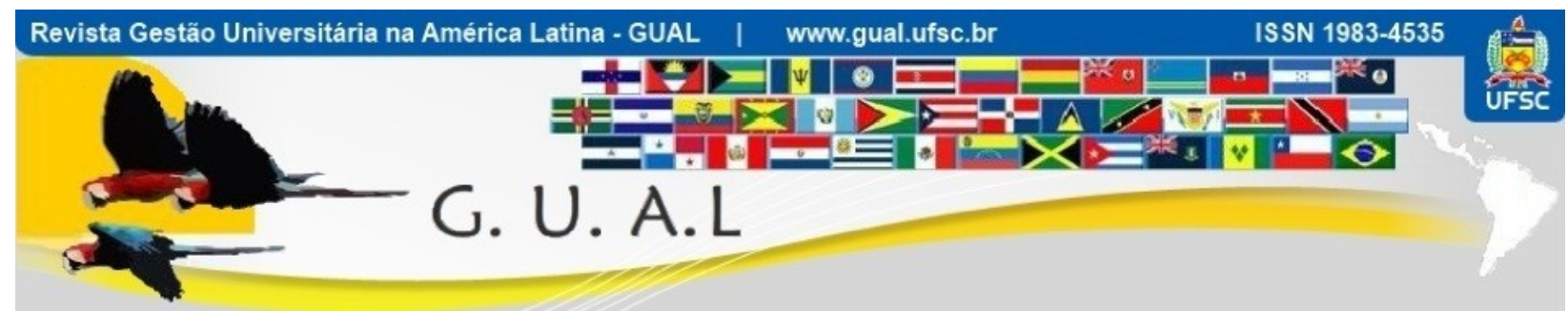

DOI: http://dx.doi.org/10.5007/1983-4535.2015v8n2p153

\title{
SUSTENTABILIDADE DAS POLÍTICAS E ESTRATÉGIAS PARA A EDUCAÇÃO SUPERIOR NO BRASIL: UMA ANÁLISE SOB A ÓTICA DA TEORIA DOS SISTEMAS AUTOPOIÉTICOS
}

\section{SUSTAINABILITY POLICIES AND STRATEGIES FOR HIGHER EDUCATION IN BRAZIL: AN ANALYSIS FROM THE PERSPECTIVE THEORY OF AUTOPOIETIC SYSTEMS}

\author{
Angela Cristina Correa, Doutora \\ Universidade Federal de Santa Catarina - UFSC \\ angelaccorrea@gmail.com \\ Lucas Veiga Ávila, Doutorando \\ Universidade Federal de Santa Maria - UFSM \\ admlucasveiga@gmail.com \\ Vitor Francisco Schuch Júnior, Doutor \\ Universidade Federal de Santa Maria - UFSM \\ vfschuch@gmail.com
}

Lucia Rejane Da Rosa Gama Madruga, Doutora Universidade Federal de Santa Maria - UFSM luciagm@ufsm.br

Celina Franco Hoffmann, Doutoranda Universidade Federal de Santa Maria - UFSM celina hoffmann@hotmail.com

Rolf Hermann Erdmann, Doutor Universidade Federal de Santa Catarina - UFSC erdmann@cse.ufsc.br

Recebido em 13/outubro/2013

Aprovado em 17/abril/2015

Sistema de Avaliação: Double Blind Review

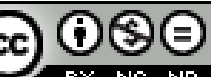

Esta obra está sob uma Licença Creative Commons Atribuição-Uso. 


\title{
RESUMO
}

Este estudo tem como objetivo analisar a abordagem da sustentabilidade na trajetória da educação superior no Brasil sob os fundamentos da teoria dos sistemas autopoiéticos. Trata-se de um estudo exploratório de caráter qualitativo, que buscou identificar os principais fenômenos que determinaram a trajetória e evolução histórica das políticas e estratégias para a educação superior. No que se refere à evolução da Educação Superior, pode-se verificar que ocorreu de forma tardia, passando as Universidades por um amplo processo regulatório e vários acontecimentos marcantes. A ótica da Sustentabilidade, em especial a Educação para Sustentabilidade, está em processo evolutivo. Como resultados mais expressivos, as evidências apontam que o Brasil tem sido um forte aliado da Organização das Nações Unidas - ONU, na busca do fortalecimento de estratégias e ações para a sustentabilidade; importante ator para a criação de normas de certificação como a ISO; inserção de novas politicas de avaliação e controle na educação pelo Ministério da Educação - MEC e seus conselhos; criação do planejamento para as instituições de ensino, denominado de Plano de Desenvolvimento Institucional - PDI; inclusão da educação ambiental nas diretrizes curriculares de cursos de nível superior entre outros; novos processos e politicas para a qualificação do ensino; novos modelos de gestão, em especial para a operacionalização do PDI em Instituições de Educação Superior (IES).

Palavras-chave: Educação Brasileira. Políticas. Estratégias. Sistemas Aupoiéticos.

\begin{abstract}
This study aims to analyze the sustainability approach in the history of higher education in Brazil under the foundations of the theory of autopoietic systems. This is an exploratory qualitative, aimed at identifying the key phenomena that determine the trajectory and historical evolution of policies and strategies for higher education. With regard to the evolution of higher education, it can be verified that occurred so late, through the Universities for a broad regulatory process and several key events. The perspective of sustainability, especially Education for Sustainability, is in the process of evolution. As more significant results, evidence shows that Brazil has been a strong ally of the United Nations - UN , in seeking to strengthen strategies and actions for sustainability; important actor for the creation of certification standards such as ISO; insertion new policy evaluation and control in education by the Ministry of education - MEC (in the Portuguese acronym) and their counsel; creation of planning for educational institutions, called the Institutional Development Plan IDP; inclusion of environmental education in the curriculum guidelines of college-level courses between others, new processes and policies for the education qualification, new management models, especially for the operationalization of PDI in Higher Education Institutions ( HEI).
\end{abstract}

Keywords: Brazilian Education. Policies. Strategies. Autopoietic systems. 


\section{SUSTENTABILIDADE DAS POLÍTICAS E ESTRATÉGIAS PARA A EDUCAÇ̃̃O SUPERIOR NO \\ BRASIL: UMA ANÁLISE SOB A ÓTICA DA TEORIA DOS SISTEMAS AUTOPOIÉTICOS \\ DOI: http://dx.doi.org/10.5007/1983-4535.2015v8n2p153}

\section{INTRODUÇÃO}

A identidade de um sistema organizacional pode ser determinada pelo seu padrão comportamental ao longo do tempo. A teoria dos sistemas autopoiéticos contrapondo-se à teoria dos sistemas abertos, salienta que os sistemas são organizacionalmente fechados, ou seja, a sua estrutura interna é responsável por configurar o seu comportamento, e a maneira como interage com o ambiente externo. As Instituições de Educação Superior (IES) têm singularidades e especificidades próprias de organizações que trabalham com um ativo intangível, que é o conhecimento produzido e disseminado à sociedade. Sob este prisma, tem objetivos multidimensionais para atingir a missão e a visão a que se destinam.

A autopoiese vem do grego autos (auto) e poiésis (criação) é um termo concebido na década de 70, pelos biólogos e filósofos chilenos: Francisco Varela e Humberto Maturana. A noção precípua, aplicada às teorias educacionais e de aprendizagem, visa que o ato de aprender decorre da própria estrutura dos seres vivos, que aprendem com a inserção no meio natural e social. Assim, a aprendizagem não estaria limitada apenas às formas tradicionais de ensino, mas envolveria a própria estrutura inerente ao ser humano, como ator político e social (NETO; GARRIDO E JUSTEN, 2011).

A perspectiva histórica da aprendizagem ressalta o papel das experiências passadas que moldam a organização na concepção atual e prediz suas rotinas. Essa busca do passado apresenta inúmeras implicações para o futuro, é preciso mapear as decisões micropolíticas, que pertencem à meticulosa reconstrução da sequência de decisões, contextos e razões que justificam as mudanças provenientes da execução da estratégia ao longo do tempo (FEAR, 2001). De fato, a aprendizagem não é uma atividade separada, mas está incorporada nos processos de trabalho e de organização, que por consequência incide na evolução histórica, este raciocícnio leva àcrer queestratégia, aprendizado e organização podem interagir dinamicamente (DIERKS et al, 2001).

Segundo Maturama e Varela (1997); Morgan (1996); e Maiula (2000), a estratégia configura-se a partir do processo de auto-referência da organização. A autopoiese aborda o sistema organizacional como sendo circunscrito, fechado, autoprodutor e reprodutor de si mesmo. A identidade estratégica da organização é o resultado de seu processo ontogênico, no acoplamento recursivo do passado com o presente. A contribuição da estratégia é dar sentido ao fluxo de eventos do processo retrospectivo, denominado sense-making, que pressupõe a existência de um equilíbrio entre planejamento, experimentação e o que é conhecido sobre o 
futuro. A elaboração da estratégia é, portanto, um processo descontínuo, sujeito aos acontecimentos ao longo da trajetória organizacional (WOLF; HEDBERG, 2001).

Diante dos pressupostos da teoria dos sistemas autopoiéticos que explicam a construção da identidade institucional, e da pertinência do enfoque sobre a sustentabilidade no contexto da Educação Superior, o presente estudo tem como objetivo analisar a abordagem da sustentabilidade na trajetória da Educação Superior no Brasil, sob os fundamentos da teoria dos sistemas autopoiéticos. Parte-se do pressuposto que a identidade do modelo da educação superior no Brasil tem como suporte o seu sistema autopoiético como processo de autoreferência. O termo sustentabilidade neste contexto tem implícita uma ideia de continuidade e responsabilidade social.

A sustentabilidade e as discussões relacionadas ao Desenvolvimento Sustentável - DS são cada vez mais recorrentes em diferentes contextos e áreas do conhecimento. Diante dos inúmeros problemas socioambientais que vêm ocorrendo nas últimas décadas,e a preocupação em garantir condições de sobrevivência para as gerações futuras, são crescentes os movimentos em prol do DS, que é definido como "desenvolvimento capaz de suprir as necessidades da geração atual, sem comprometer com a capacidade de atender as necessidades das futuras gerações" (WCED, 1987, p.9).

A segunda seção deste artigo apresenta a teoria dos sistemas autopoiéticos, a terceira seção as singularidades e especificidades das instituições de educação superior (IES); a quarta seção um histórico sobre a educação superior no Brasil; a quinta o delineamento metodológico do estudo, onde se descreve a modelagem conceitual para análise de sistemas educacionais; a sexta seção os resultados obtidos e, por fim, na sétima seção as considerações finais.

\section{A TEORIA DOS SISTEMAS AUTOPOIÉTICOS}

As teorias inseridas em uma determinada abordagem do conhecimento refletem um paradigma científico, ou seja, um modelo de mundo, percepções e valores inerentes a um contexto histórico e social. As teorias nada mais são do que a linguagem utilizada para dialogar com o mundo. Em outras palavras pode-se dizer que existem diferentes linguagens que expressam um determinado paradigma.

A teoria dos sistemas autopoiéticos, originária da biologia, tem sido aplicada em diversas áreas do conhecimento. No campo da gestão organizacional, seus fundamentos 
conceituais são aplicados para o estudo da estratégia como um processo de auto-referência organizacional.

Johannessen (1998, p. 361) subdivide a cibernética em duas ordens: clássicas ou de primeira-ordem, baseada no positivismo e a de segunda-ordem orientada e focada na interrelação observador-fenômeno, no sistema social, as quais se enquadram na teoria autopoiética.

De acordo com Maturana e Varela (1997, p.11) numa percepção diferente da teoria de Von Bertalanfy, que aborda os seres vivos como sistemas abertos, processadores de energia, argumentam que os seres vivos são organizacionalmente fechados. Expõem que o processo de auto-referência é o que determina a maneira como se relacionam com o ambiente externo. Sob este enfoque salientam que: “[...] todos os fenômenos biológicos acontecem por meio da realização individual dos seres vivos".

Ainda conforme os autores supracitados, a autopoiese é considerada uma rede de produções de componentes, que resulta fechada sobre si mesma, porque os componentes que produz a constituem ao gerar as próprias dinâmicas de produções e ao determinar sua extensão como um ente circunscrito, por meio do qual existe um contínuo fluxo de elementos que se tornam e deixam de ser componentes, conforme participam ou deixam de participar nessa rede.

Morgan (1996) descreve a teoria dos sistemas autopoiéticos, como a lógica dos sistemas autoprodutores, que parte da ideia, de que todos os sistemas vivos são organizacionalmente fechados, bem como sistemas autônomos de interação, e que fazem referência somente a eles mesmos. Contrapõe-se a ideia de que os sistemas vivos são abertos em relação ao ambiente, cuja concepção é, segundo eles, o produto de uma tentativa de dar sentido a tais sistemas a partir do ponto de vista do observador externo. Oferece uma nova perspectiva para compreender à lógica,por meio da qual os sistemas vivos mudam.

Na interpretação de Morgan (1996) Humberto Maturana e Francisco Varela utilizaram o termo autopoiesis para se referirem à capacidade de auto-reprodução, por meio de um sistema fechado de relações. Sustentam que o objetivo de tais sistemas é, em última instância, reproduzirem-se a si mesmos, a sua organização e identidade próprias são os seus produtos mais importantes.

Deduz-se do exposto que a percepção do sistema autopoiético organizacional, pelo agente observador, como uma unidade auto-referente, que opera numa cadeia circular 
fechada, delimita as fronteiras entre os fatores restritivos e impulsionadores internos e externos que impactam a estratégia organizacional. Este estudo ao aplicar os fundamentos da teoria de sistemas autopoiéticos, utilizando a técnica de observação como um ato de abstração, tem o propósito de analisar os principais fatos históricos que determinam o padrão comportamental implícitos nas políticas e estratégias para a educação superior ao longo do tempo.

\section{PRINCIPAIS MARCOS HISTÓRICOS DA EDUCAÇÃO SUPERIOR NO BRASIL}

A Universidade como instituição formal, existe já há quase IX séculos, de acordo com Schuch Jr. (2005) evidentemente ela evoluiu muito, desde a fundação de Bolonha, Paris e Oxford. Tanto pelas influências civis, religiosas, sociais, econômicas quanto o desenvolvimento da ciência inspiraram ou tornaram obrigatória esta evolução. No entanto, todos os sistemas de Ensino Superior ou todos os estabelecimentos não evoluíram com o mesmo ritmo e com as mesmas características. Universidades como instituições formais existem já há quase nove séculos, tendo evoluído desde a fundação de Bolonha, Paris e Oxford pelas influências civis, religiosas, sociais, econômicas e também pelo desenvolvimento da ciência por meio do qual inspiraram ou tornaram obrigatória esta evolução.

Estudos de Schuch Jr. (1995) relacionam que a primeira Universidade a ser fundada foi em 1088 na Itália, a de Bolonha. Após 12 anos, surge a Universidade de Oxford em 1096, no Reino Unido. Já na América Latina, a primeira foi a de Lima, no Peru. No Brasil, a Universidade surgiu tardiamente e com características bem peculiares. Surgiu e se consolidou em escolas superiores isoladas com orientação precipuamente voltada para a preparação profissional naquelas áreas mais tradicionais que as elites emergentes do país demandavam.

Segundo Cunha (2007) as universidades não foram mais do que a reunião desses estabelecimentos isolados que relutaram em articularem-se numa nova instituição, mantendo seu status particular e características originárias. As primeiras experiências de ensino superior no Brasil começaram a partir do ano de 1549, com a companhia de Jesus. O primeiro colégio dos Jesuítas foi fundado em 1553, porém, somente no século XVI, iniciavam-se as primeiras experiências de ensino superior. Em 1759 os Padres jesuítas foram expulsos do país, e houve "uma desarticulação do sistema educacional escolar da colônia". Iniciava-se uma longa história de intervenção do Estado na dinâmica da educação do Brasil. 


\section{SUSTENTABILIDADE DAS POLÍTICAS E ESTRATÉGIAS PARA A EDUCAÇ̃̃O SUPERIOR NO \\ BRASIL: UMA ANÁLISE SOB A ÓTICA DA TEORIA DOS SISTEMAS AUTOPOIÉTICOS \\ DOI: http://dx.doi.org/10.5007/1983-4535.2015v8n2p153}

Os Franciscanos criaram, em 1776, um curso superior de que Direito, no convento Santo Antônio, na cidade do Rio de Janeiro (RJ), que representava uma faculdade organizada semelhante à universidade de Coimbra. Em Olinda, o Bispo José Joaquim da Cunha Azeredo Coutinho, em fevereiro de 1800, foi o responsável pela fundação do seminário Episcopal de Olinda. No século XIX, após 1808 foram criadas uma série de Faculdades no Brasil, e o Ensino Superior começou a ganhar conotações de um sistema (CUNHA, 2007). Para o autor, o ensino superior atual nasceu, assim, com o Estado Nacional, gerado por ele e para ele cumprir, predominantemente as funções próprias deste, seguindo a mesma lógica de promover a formação dos burocratas na medida em que eles faziam necessários.

Considerando a Faculdade de Medicina no Rio de Janeiro e na Bahia, a Faculdade Politécnica do Rio de Janeiro, a Escola de Minas Gerais e a Faculdade de Direito de São Paulo e de Recife, no Brasil tinha em 1888, 2.641 estudantes matriculados, segunda a pesquisa de CUNHA (2007). Ao longo do século XIX foram criadas leis especificas para o ensino Superior. A Legislação regulamentava os currículos, a contratação de professores, a nomeação dos diretores e o reconhecimento dos diplomas, entre outros. A constituição de 1891 permitiu a expansão do ensino superior público e privado. O Congresso Nacional e as assembleias constituintes poderiam criar instituições e cursos de ensino superior. Naquele mesmo ano dois decretos foram instituídos, mas o Decreto $\mathrm{n}^{\circ} 1.232$, de 1891 , segundo Cunha criava o Conselho Superior de Instrução Superior:

Com a competência para aprovar os programas de ensino das escolas federais e das que lhes fossem equiparadas; de propor ao governo federal os regulamentos para inspeção das faculdades livres; de criar novos estabelecimentos de ensino; de nomear as comissões e os delegados estaduais para a inspeção dos estabelecimentos federais de faculdades livres.

No Brasil, o Decreto $\mathrm{n}^{\circ} 1.232$, de 1891 , permitiu que os governos estaduais e as instituições particulares fundassem escolas de direito, desde que o currículo fosse semelhante ao das Faculdades Federais. Além disso, o decreto determinava a inspeção periódica, com a visita de representantes do conselho superior. Ao mesmo tempo surgiram Faculdades independentes, que não solicitaram o reconhecimento do diploma do Governo Federal. A Escola de Engenharia da Mackenzie College e a Escola de Engenharia de Porto Alegre, ambas criadas em 1896, são a referencias de instituições que nasceram independentes, nos primeiros anos de República. Em 1923, a Escola do Mackenzie começou a expedir diplomas validados nacionalmente. Segundo Cunha, até 1910 foram criadas 27 Escolas superiores. 
Segundo INEP (2011) a Lei Orgânica do Ensino Superior e Ensino Fundamental na época da República, elaborada pelo então Ministro do Interior, Ridavádia da Cunha Lima, deu autonomia as Faculdades superiores criadas pelos governos estaduais e por instituições particulares ao determinar que não coubesse ao governo Federal o papel de Fiscalizador. As próprias instituições Federais ganharam autonomia pedagógica, administrativa e financeira. Houve muitas criticas a Lei Orgânica, fundamentadas na argumentação da proliferação das faculdades livres e no perigo da ausência de controle do Estado (Colombo e Rodrigues, 2011).

Conforme Colombo e Rodrigues (2011) em 1915, o Decreto $\mathrm{n}^{\circ} 11.530$ diminuiu a autonomia das instituições de ensino. Segundo a nova Lei, caberia ao conselho superior de ensino fiscalizar "as escolas que foram não mantidas pelos governos federais, as quais foram obrigadas a pagar uma taxa de fiscalização para cobrir as visitas”. Segundo Cunha (2007, p. 168) caberia "ao inspetor do conselho atestar o bom funcionamento da faculdade, a existência da moralidade acadêmica, a qualificação do corpo docente e adequação do material didático". As faculdades particulares e livres deveriam solicitar a validação do diploma.

Após esses processos, Colombo e Rodrigues (2011) salientam que entra em ação o Decreto $\mathrm{n}^{\circ} 16.782$ de 1925, que institui o Departamento Nacional de Ensino e substitui o Conselho Superior de Ensino pelo Conselho Nacional de Ensino. A mudança foi realizada com objetivo de intensificar o controle do Governo Federal sobre as instituições de ensino e “impedir a entrada da política e da ideologia não oficiais do Ensino Superior”. Iniciava-se uma fase de tensão entre a iniciativa privada, que reivindicava autonomia diante do Estado Federal, no sentido de poder fundar suas instituições, fazer a gestão e validar seus diplomas com o governo, o qual procura intensificar o controle do Governo Federal sobre as instituições de ensino e "impedir a entrada da política e da ideologia não oficiais do ensino superior".

Segundo Speller (2012) a educação superior obteve forte expansão a partir da década de 1970, com instância da formação profissional, por meio do setor privado, que deste então, tornou-se hegemônico na oferta de educação superior. Segundo o mesmo autor, neste período o Governo Federal instituiu alguns mecanismos e instituições com o objetivo de tornar algumas IES públicas em centros de excelência. Como resultado, o Brasil passou a contar com uma maioria de instituições de natureza privada, ocupadas da certificação para o exercício profissional, ao mesmo tempo em que com algumas poucas instituições públicas, 
localizadas nos grandes centros urbano sem nível de pós-graduação e da produção de conhecimento, voltadas à pesquisa.

Speller (2012) et al Saviani (2010) salientam que a Constituição Federal de 1988 consagrou a autonomia universitária, estabeleceu a indissociabilidade entre ensino pesquisa e extensão, garantiu a gratuidade nos estabelecimentos oficiais, assegurou o ingresso por concurso público e o regime jurídico único. A demanda dos dirigentes de instituições de ensino superior públicas e de seu corpo docente encaminhou-se na direção de uma dotação orçamentária que viabilizasse o exercício pleno da autonomia e, da parte dos alunos e da sociedade, de modo geral, o que se passou a reivindicar foi a expansão das vagas das universidades públicas.

As disparidades econômicas contribuíram muito para aumentar a diferença em termos de acesso e qualidade da educação de nível superior entre os países desenvolvidos e os países em desenvolvimento. Speller (2012) expõe que no caso do Brasil, a partir da década de 1990, teve início uma nova fase de expansão da educação e o Ensino Superior, especialmente o de graduação, que viveu uma enorme transformação e evolução que pode ser explicitada por meio do número de instituições de ensino, de cursos e vagas ofertadas. Segundo este mesmo autor, visando oferecer um panorama da Educação Superior representativo da evolução de 2001 a 2010, os dados compilados do Censo do Instituto Nacional de Estudos e Pesquisas Educacionais Anísio Teixeira (INEP) apresentam uma expressiva evolução do sistema.

Segundo dados do INEP (2012) em 2010 o Brasil contava com 6.379.299 matrículas em cursos de graduação, esse total representa mais que o dobro das matrículas de 2001.Apesar do caráter preponderantemente privado da expansão ao longo desse período, tais resultados apontam para certa estabilização da participação desse setor, que, em 2010, atende a $74,2 \%$ das matrículas. Por outro lado, nesse mesmo período, o setor público assiste a uma significativa expansão. As categorias federal e estadual apresentam crescimento no número de matrículas de 2001 a 2010 da ordem de $85,9 \%$ e $66,7 \%$, respectivamente.

\section{SUSTENTABILIDADE}

O conceito de sustentabilidade e as discussões relacionadas ao Desenvolvimento Sustentável - DS, do Planeta são cada vez mais recorrentes em diferentes contextos e áreas do conhecimento. Em virtude dos inúmeros problemas sociais e ambientais que vêm ocorrendo nas últimas décadas a fim de garantir condições de sobrevivência para as gerações futuras, são 
crescentes os movimentos em prol do DS, definido como o "desenvolvimento capaz de suprir as necessidades da geração atual, sem comprometer com a capacidade de atender as necessidades das futuras gerações" (WCED, 1987 p.9).

Gerações futuras, aquecimento global, inclusão, conectividade, equidade prudência e segurança parecem ser tópicos não comumente tratados pela lógica organizacional. O DS nas organizações, quando considerado da forma incondicional, tudo em vista à sua própria existência questiona-se na distribuição da riqueza gerada, á lógica do incentivo ao consumo, suas relações com o entorno, sua forma de lidar com os empregados, o futuro da humanidade, uma vivência independente e inserida em sociedade (ESTEVES, 2009).

Ben-Eli (2006) compara o DS com o sucesso de um voo de uma aeronave. Uma vez que, para ter sucesso é necessário que os operadores responsáveis conheçam os princípios básicos da aerodinâmica. Da mesma maneira, para entender o processo do DS, é preciso guiar-se por um conjunto de princípios que fundamentam a sustentabilidade como um estado permanente.

Vários autores conceituam sustentabilidade procurando encontrar uma forma sistemática para operacionaliza-la nas organizações. A operacionalização do conceito de DS ganhou diversas conotações e vários modelos alcançaram destaque, tendo no meio acadêmico, quanto empresarial. Um dos principais modelos, que procurou reduzir a sustentabilidade a um padrão mínimo de operacionalização é o denominado Triple BottonLine - TBL conhecido como Tripé da Sustentabilidade, de Elkington (1997).

Elkington (1997, p.20) define a sustentabilidade como o "principio de assegurar que nossas ações hoje não limitarão a gama de opções econômicas, sociais e ambientais disponíveis para as gerações futuras". Ele operacionaliza o conceito em três pilares: econômico, social e ambiental, como apresenta a Figura 01. 


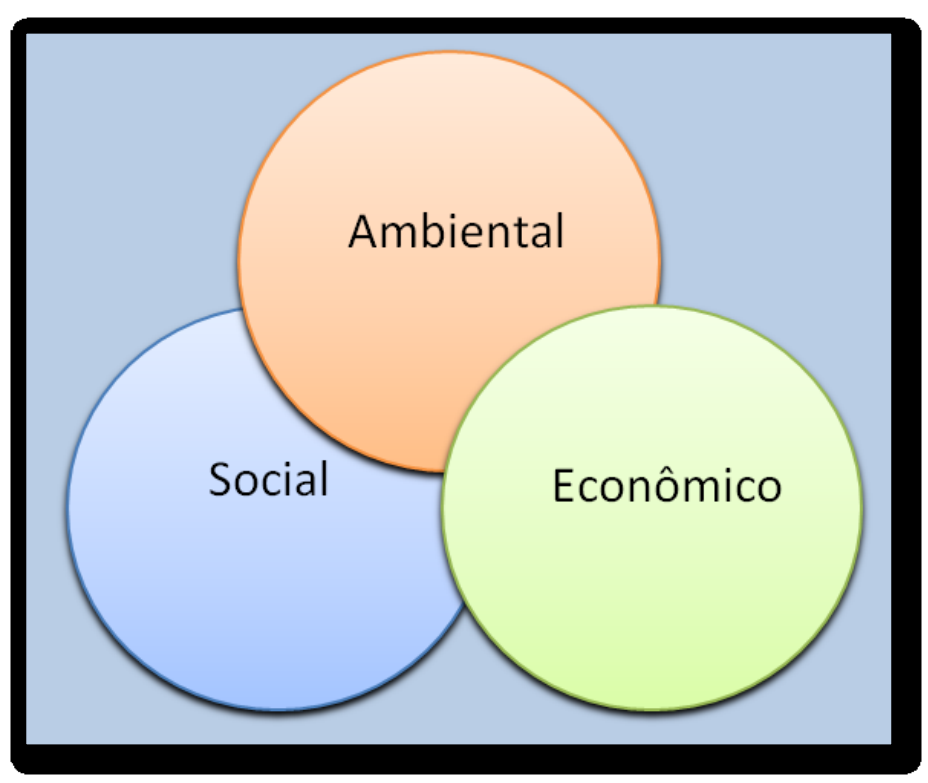

Figura $01 \mathrm{O}$ TBL

Fonte: Elkington (1997, p. 87)

Para Elkington (1997) as dimensões da sustentabilidade estão intrínsecas no conceito de empresa sustentável, representadas no livro Cannibals with Forks: The Triple Bottom Line of, tendo seu conceito apresentado por meio de uma metáfora de um garfo composto por três dentes. Cada dente refere-se às dimensões econômica, social e ambiental da sustentabilidade em termos de resultados líquidos, procurando responder à pergunta: o capitalismo, assim como um canibal, se tornaria civilizado utilizando o garfo?

As três dimensões da sustentabilidade, comumente denominadas como tripé da sustentabilidade devem estar integradas, de modo que, na esfera ambiental, os recursos sejam aproveitadas de maneira eficaz.

A sustentabilidade é entendida por meio do processo do desenvolvimento sustentável, que surgiu em 1980 e foi consagrado em 1987 pela Comissão Mundial sobre o Meio Ambiente e Desenvolvimento, Comissão Brundtland, ao produzir um relatório considerado básico para a definição deste conceito. Os princípios do desenvolvimento sustentável estão na base da Agenda 21, documento aprovado por mais de 170 países durante a realização da Conferência das Nações Unidas sobre Meio Ambiente e Desenvolvimento, realizada no Rio de Janeiro em 1992, a Rio92 (BARBIERI, 2012).

No âmbito dos eventos, destacam-se a Declaração de Talloires na França, de 1950, que reuniu mais de 400 universidades de várias regiões do mundo, e a declaração de Luneburg de 2001, que reuniu 1.000 instituições na Global Higher Education For 
Sustainability - GHESP, Conferência sobre o Ensino Superior para o DS. Mais recentemente em 2009 evidencia-se a Alternative University Appraisal - AUA, Comunidade das Universidades Asiáticas, que visa fortalecer as estratégias para Educação para a Sustentabilidade, como um pacto global (TERMIGNONI, 2012). Segunda a autora, a Educação para a Sustentabilidade adquiriu grande importância devido ao movimento pelo DS. O final do século XX e o início do século XXI foram marcados pela criação de diferentes organizações voltadas para esta finalidade. Em, 1995 foi criada a Organização Internacional de Universidades pelo Desenvolvimento Sustentável e Meio Ambiente - OIUDSMA, a Parceria Global do Ensino Superior para o Desenvolvimento Sustentável - PGDS e realizada a Environmental Management for Sustainable Universities - EMSU, Conferência Internacional sobre Gestão Ambiental para as Universidades Sustentáveis.Nesses eventos torna-se necessário salientar que as Instituições e os conselhos do país, sempre se fizeram presentes das discussões, bem como o Brasil tornou-se um forte aliado desse processo com a ONU.

Diante do exposto, pode-se averiguar que a educação superior no Brasil está em processo evolutivo, a cada ano, novas diretrizes, plano ações estão contribuindo para o aumento e proliferação de tal conceito. Uma vez que, esse processo comparado com outras realidades ainda é bastante peculiar, sendo considerado aquém dos rankings de qualidade. É necessário melhorar e qualificar o ensino, não apenas aumentar o número de instrução da população. Uma das políticas pode ser relacionado ao planejamento de politicas que envolvam desde a formação de séries iniciais, para a formação de crianças, jovens com a percepção e preocupação da importância da sustentabilidade nos diferentes contextos.

Os avanços desse sistema ocorreram a partir de 1990, quando a população jovem começou a ter uma relação de apoio com as plataformas tecnológicas. Para Alves (2013) os brasileiros nascidos na década de 90, foram alfabetizados ouvindo falar em sustentabilidade e já com algum contato com a internet. Alves (2013) salienta, que o momento atual, os jovens passaram a ser chamados de Geração Digital, pois possuem características peculiares que os diferenciam das gerações anteriores, sobretudo pela forma como se relacionam entre si e com o mundo por meio dos recursos digitais de comunicação. Essa geração é componente da geração Y. Nas pesquisas de Alves (2013), destacam-se alguns autores, em especial estudos de (Tapscott, 1997; Prensky, 2001; Palfrey e Gasser, 2011; Veen e Vrakking, 2009; Nielsen, 2013) que se referem a estes jovens como sendo da geração Y, Geração Digital, geração Z ou C, entre outros nomes. Ainda segundo Alves (2013), na literatura de (Hawcroft e Milfont, 
2010), os autores espera-se que os mais jovens apresentem um nível de consciência ambiental maior do que as gerações que os antecederam, que o nível de consciência ambiental seja diretamente proporcional à escolaridade, diretamente proporcional à renda e que seja maior entre as mulheres do que entre os homens.

Termignoni (2012) salienta que um dos caminhos que fortalece o Sistema de Educação Brasileiro, pois as universidades se esforçaram para definir e ao mesmo tempo assumir seu papel no que se refere ao ensino para um futuro viável, sendo as declarações verificadas nos encontros de âmbito internacional as suas respostas. Nesse viés, Zitzke (2002), destaca que a educação tem importante papel para o DS, mais especificamente relacionada com a dimensão ambiental (.....) atuando como tradutora do conhecimento técnico e científico para a compreensão de todos os envolvidos nas questões ambientais, (...) pode induzir ao pensamento crítico, a buscar demonstrações ou justificativas e a não aceitar sem análise a implantação de qualquer projeto que ofereça riscos sociais ou ambientais.

Shrivastava (2010) salienta que nossas práticas atuais de ensino na gestão sustentável estão repletas de fatos científicos, ferramentas analíticas, modelos de otimização e técnicas de gestão. Um dos pilares para a aprendizagem da sustentabilidade na educação é a pedagogia da paixão. O autor salienta que o objetivo pedagógico é ajudar os alunos compreenderem e resolverem problemas. Ele argumenta, a favor de um enfoque diferente para ensinar sustentabilidade. Gerir de forma sustentável requer os alunos a desenvolverem a paixão pela sustentabilidade. Paixão para a sustentabilidade pode ser ensinada utilizando uma pedagogia holística que integra a aprendizagem física e emocional ou espiritual com cognitivo (intelectual) de aprendizagem tradicional sobre o manejo sustentável.

\section{MÉTODO}

A presente pesquisa caracteriza-se como exploratória, que segundo Hair et al. (2005) é utilizada para que seja desenvolvida uma melhor compreensão do problema de pesquisa. Visando atingir os objetivos propostos, o estudo foi desenvolvido a partir de uma abordagem qualitativa, pois realizou-se estudos de observação em documentos na literatura. Este tipo de pesquisa caracteriza-se como a tentativa de uma compreensão detalhada dos significados e características situacionais apresentadas (RICHARDSON, et al. 1999, p. 90).

A Concepção filosófica da ciência que caracteriza um estudo representa um paradigma em que determinado fenômeno físico, humano ou social, objeto de investigação, está inserido. 
O paradigma é um modelo de abordagem que traduz o pensamento da humanidade. As teorias inseridas nas abordagens representam o conhecimento sistematizado. Visam fornecer explicações parciais da realidade.

Segundo Corrêa et al. (2003) inserem a abordagem quântica como um paradigma alternativo da ciência, na taxionomia das suas concepções filosóficas, a qual agrega o ponderável, previsível, linear e passível de medição e determinação ao imponderável, imprevisível e não linear passível de observação. Salientam que esta concepção científica possui características comuns à abordagem sistêmica, tais como o enfoque sistêmico e a relação de causalidade probabilística entre as variáveis. Apresenta como diferenciais a observação enquanto ato de percepção, na relação entre observador e objeto, a dualidade e a complementaridade dos fenômenos.

Este estudo se enquadra na abordagem quântica sob os fundamentos da teoria dos sistemas autopoiéticos. Consiste em um estudo qualitativo de caráter exploratório. Utilizou-se a técnica de observação enquanto ato de percepção. Os autores de estudo procederam a uma análise sob o prisma da autopoiese, dos principais fenômenos que determinaram a evolução histórica das políticas e estratégias para a educação superior no Brasil.

\subsection{MODELAGEM CONCEITUAL: ESTRUTURA DE REFERÊNCIA}

No Quadro 01 apresenta-se a modelagem conceitual proposta para estudos da identidade autopoiética de sistemas organizacionais.

\begin{tabular}{|l|l|l|}
\hline \multicolumn{2}{|c|}{ MODELAGEM CONCEITUAL: IDENTIDADE AUTOPOIÉTICA DE SISTEMAS } \\
ORGANIZACIONAIS
\end{tabular}

Quadro 01 Modelagem conceitual de análise de sistemas autopoiéticos

Fonte: Elaborado com base em Maturama e Varela (1997), Morgan (1996) e Maiula (2000)

Inicia-se com o processo de autoconhecimento (autopoiese) do sistema organizacional objeto de análise. O senso de auto-referência do sistema é um círculo fechado, produtor e auto reprodutor de si mesmo. O sistema autopoiético é definido a partir do processo ontogênico, ou seja, transformação das políticas e estratégias da educação superior ao longo do tempo. 
A autopoiese está fundamentada na compreensão que cada sistema tem um domínio fenomenológico próprio. Pressupõe que o sistema tem uma identidade própria, única que é estabelecida pela sua ontogenia. No processo ontogênico do sistema autopoiético, padrões recursivos de comportamento são acoplados ao presente, com conservação de identidade, por meio de sua autopoiese continuada no espaço físico. A recursividade se refere à repetição dos padrões de comportamento e o acoplamento às contingências históricas passadas somadas ao presente.

A configuração do autopoiese do sistema considera as suas contingências históricas, sua ontogenia, morfogênese organizacional (configuração e estrutura), suas propriedades de recursividade (repetição dos padrões estratégicos implícitos) e acoplamento (contingências históricas passadas somadas ao presente), as quais determinam a sua estrutura interna, ou seja, seu senso de identidade.

A análise do sistema autopoiético proposta por Maiula(2000) consiste na identificação de duas funções: a função de memória auto-referente organizacionalmente fechada e a função de memória aberta e interativa.

A análise da evolução das políticas e estratégias para a educação superior apresentada na seção seguinte, parte da observação enquanto ato de percepção dos pesquisadores dos principais fatos que consolidaram o padrão arquétipo comportamental das políticas e estratégias para a educação superior ao longo do tempo. Conclui-se a análise com uma apreciação crítica do comportamento do sistema no momento atual e as perspectivas futuras.

\section{ANÁLISE DA EVOLUÇÃO DA EDUCAÇÃO SUPERIOR SOB OS FUNDAMENTOS DA TEORIA DOS SISTEMAS AUTOPOIÉTICOS}

No Quadro 02 apresenta a análise da evolução da Educação Superior com base na modelagem proposta para o reconhecimento da identidade autopoiética de sistemas (cf. Quadro 1). 


\section{SUSTENTABILIDADE DAS POLÍTICAS E ESTRATÉGIAS PARA A EDUCAÇÃO SUPERIOR NO BRASIL: UMA ANÁLISE SOB A ÓTICA DA TEORIA DOS SISTEMAS AUTOPOIÉTICOS DOI: http://dx.doi.org/10.5007/1983-4535.2015v8n2p153}

\begin{tabular}{|c|c|}
\hline \multicolumn{2}{|c|}{ AUTOPOIESE SISTEMA EDUCAÇÃO SUPERIOR NO BRASIL } \\
\hline $\begin{array}{l}\text { FASES DO PROCESSO } \\
\text { ONTOGÊNICO }\end{array}$ & $\begin{array}{c}\text { CONTINGÊNCIAS HISTÓRICAS } \\
\text { ACOPLAMENTO RECURSIVO PASSADO EPRESENTE }\end{array}$ \\
\hline $\begin{array}{l}\text { 1 } 1^{\mathrm{a}} \mathrm{FASE} \\
\text { Primeiras experiências de } \\
\text { ensino superior no Brasil } \\
\text { iniciaram no século XVI }\end{array}$ & $\begin{array}{l}\text { Em } 1776 \text { os Franciscanos criaram um curso superior de direito no convento } \\
\text { Santo Antônio, na cidade do Rio de Janeiro (RJ). Acessível somente pela elite } \\
\text { da sociedade }\end{array}$ \\
\hline $\begin{array}{l}2^{\mathrm{a}} \mathrm{FASE} \\
\text { No século XIX, após } 1808 \\
\text { foram criadas várias } \\
\text { faculdades no Brasil }\end{array}$ & $\begin{array}{l}\text { O ensino superior começou a ganhar conotações de um sistema. Permaneceu } \\
\text { com a mesma configuração durante o "Brasil Imperial". Visava } \\
\text { precipuamente à formação de burocratas. Faculdades criadas: Faculdade de } \\
\text { Medicina no Rio de Janeiro e na Bahia, a Faculdade Politécnica do Rio de } \\
\text { Janeiro, a Escola de Minas Gerais e a Faculdade de Direito de São Paulo e de } \\
\text { Recife, com } 2641 \text { alunos matriculados (1808). }\end{array}$ \\
\hline $\begin{array}{l}3^{\mathrm{a}} \text { FASE } \\
\text { Expansão do ensino } \\
\text { superior público e privado } \\
\text { (longo do século XIX - } \\
\text { Constituição de 1891). }\end{array}$ & $\begin{array}{l}\text { Criação de leis regulatórias especifica para o ensino superior: legislação } \\
\text { regulamentando os currículos, a contratação de professores, a nomeação dos } \\
\text { diretores e o reconhecimento dos diplomas, entre outras ações. }\end{array}$ \\
\hline $\begin{array}{l}4^{\mathrm{a}} \mathrm{FASE} \\
\text { O Congresso Nacional e as } \\
\text { 168Assembleias } \\
\text { constituintes poderiam criar } \\
\text { instituições e cursos de } \\
\text { ensino superior. }\end{array}$ & $\begin{array}{l}\text { O Decreto } n^{\circ} 1.232 \text {, de } 1891 \text {, cria o Conselho Superior de Instrução Superior. } \\
\text { Tem a função de aprovar programas, regulamentar e fiscalizar a educação } \\
\text { superior no país. As faculdades recebiam visitas periódicas do Conselho de } \\
\text { Educação Superior. }\end{array}$ \\
\hline $\begin{array}{l}5^{\mathrm{a}} \mathrm{FASE} \\
\text { Criação de IES } \\
\text { independentes }\end{array}$ & $\begin{array}{l}\text { A Escola de Engenharia da Mackenzie College e a Escola de Engenharia de } \\
\text { Porto Alegre, ambas criadas em 1896, são referência de instituições que } \\
\text { nasceram independentes, nos primeiros anos de República. Até } 1910 \text { foram } \\
\text { criadas } 27 \text { Escolas superiores. }\end{array}$ \\
\hline $\begin{array}{l}\quad 6^{\mathrm{a}} \mathrm{FASE} \\
\text { Reforma Universitária }\end{array}$ & $\begin{array}{l}\text { DECRETO N. 8.659 - DE } 5 \text { DE ABRIL DE } 1911 \text { - Aprova a lei Orgânica } \\
\text { do Ensino Superior (Rivadávia Correia) e do Fundamental na República - } \\
\text { Deu autonomia as IES públicas e privadas. AS IFES ganharam autonomia } \\
\text { pedagógica, administrativa e financeira. Houve resistências a Lei Orgânica } \\
\text { fundamentadas na argumentação da proliferação das faculdades livres e no } \\
\text { perigo da ausência de controle do Estado. }\end{array}$ \\
\hline $\begin{array}{l}7^{\mathrm{a}} \text { FASE } \\
\text { Estado assume o papel de } \\
\text { fiscalizador }\end{array}$ & $\begin{array}{l}\text { Decreto } \mathrm{n}^{\circ} 11.530 \text { de } 1915 \text {, diminuiu a autonomia das instituições de ensino } \\
\text { estabelecendo que o conselho superior de ensino exercesse o papel } \\
\text { fiscalizador. Visita de inspetores pagas pelas IES; as IES particulares e livres } \\
\text { deveriam solicitar a validação de diplomas para o Estado. }\end{array}$ \\
\hline $\begin{array}{c}\text { Plano ATCON (1965 - } \\
1966)\end{array}$ & $\begin{array}{l}\text { Rudolph Atcon trabalhou com Anísio Teixeira na organização da CAPES e } \\
\text { também como subdiretor do Programa Universitário, no período de } 1953 \text { a } \\
\text { 1956. Realizou um estudo para reformulação da estrutura das universidades } \\
\text { brasileiras intitulado: "Rumo à Reformulação Estrutural da Universidade } \\
\text { Brasileira", posteriormente, publicado pelo MEC em } 1966 .\end{array}$ \\
\hline $\begin{array}{l}\text { Organização e } \\
\text { funcionamento do Ensino } \\
\text { Superior }-(1968)\end{array}$ & $\begin{array}{l}\text { Lei } \mathrm{n}^{\circ} \text { 5.540/1968 em introduzir a indissociabilidade entre o ensino e a } \\
\text { pesquisa. Fixa normas de organização e funcionamento do ensino superior e } \\
\text { sua articulação com a escola média, e dá outras providências. }\end{array}$ \\
\hline $\begin{array}{l}\text { 8 FASE } \\
\text { O processo de expansão } \\
\text { da pós-graduação - (1975- } \\
\text { 1979) }\end{array}$ & $\begin{array}{l}\text { O Plano Nacional de Pós-graduação partiu da constatação de que o processo } \\
\text { de expansão da pós-graduação havia sido até então parcialmente espontâneo, } \\
\text { desordenado e pressionado por motivos conjunturais. A partir daquele } \\
\text { momento, a expansão deveria tornar-se objeto de planejamento estatal, } \\
\text { considerando a pós-graduação como subsistema do sistema universitário e } \\
\text { este, por sua vez, do sistema educacional. A Pós-Graduação deveria, então, } \\
\text { estar integrada às políticas de desenvolvimento social e econômico e, assim, } \\
\text { ao II Plano Nacional de Desenvolvimento (PND), através do Plano Setorial } \\
\text { de Educação e Cultura (PSEC) e ao II PBDCT (Plano Básico de } \\
\text { Desenvolvimento Científico e Tecnológico), para o período 1975-1980. }\end{array}$ \\
\hline $9^{\mathrm{a}} \mathrm{FASE}$ & Decreto $^{\circ} 16.782-\mathrm{A}$, de 1925 , o qual institui o Departamento Nacional de \\
\hline
\end{tabular}




\section{SUSTENTABILIDADE DAS POLÍTICAS E ESTRATÉGIAS PARA A EDUCAÇÃO SUPERIOR NO BRASIL: UMA ANÁLISE SOB A ÓTICA DA TEORIA DOS SISTEMAS AUTOPOIÉTICOS DOI: http://dx.doi.org/10.5007/1983-4535.2015v8n2p153}

\begin{tabular}{|c|c|}
\hline $\begin{array}{l}\text { Intensificação do controle } \\
\text { do Governo Federal sobre } \\
\text { as instituições de ensino }\end{array}$ & $\begin{array}{l}\text { Ensino - DNE e substitui o Conselho Superior de Ensino - CSE pelo } \\
\text { Conselho Nacional de Ensino - CNE. Finalidade: "impedir a entrada da } \\
\text { política e da ideologia não oficiais do Ensino Superior" }\end{array}$ \\
\hline $\begin{array}{l}\text { Programa de Avaliação de } \\
\text { Reforma Universitária - } \\
\text { PARU (1983) }\end{array}$ & $\begin{array}{l}\text { Programa de Avaliação de Reforma Universitária - PARU (1983), instituído } \\
\text { em } 1983 \text { pelo Ministério da Educação e da Cultura, surge de iniciativas da } \\
\text { Associação Nacional de Docentes (ANDES). Criado pela Ministra da } \\
\text { Educação e Cultura Ester de Figueiredo Ferraz, com apoio da Financiadora } \\
\text { de Estudos e Projetos (FINEP) e coordenado pela CAPES, foi elaborado por } \\
\text { um Grupo de Trabalho composto, majoritariamente, de membros da } \\
\text { comunidade universitária. }\end{array}$ \\
\hline $\begin{array}{l}\text { Relatório do Grupo } \\
\text { Executivo para a } \\
\text { Reformulação do Ensino } \\
\text { Superior (GERES): } 1986 .\end{array}$ & $\begin{array}{l}\text { Portaria } n^{\circ} 100 \text {, de } 6 \text { de fevereiro de 1986, e instalado pela Portaria } n^{\circ} 170 \text {, de } \\
3 \text { de março de } 1986 \text {. Como uma continuidade ao trabalho da Comissão para a } \\
\text { Reformulação da Educação Superior. O objetivo do MEC era analisar a } \\
\text { validade das proposições do Relatório "Uma nova política para a educação } \\
\text { superior brasileira". }\end{array}$ \\
\hline \begin{tabular}{|}
$10^{\mathrm{a}}$ FASE \\
Início do processo de \\
criação de cultura da \\
avaliação no sistema de \\
educação superior do Brasil \\
(década de noventa). \\
\end{tabular} & $\begin{array}{l}\text { Experiências de avaliação que repercutiram de forma positiva: PAIUB (1993; } \\
\text { Exame Nacional de Cursos ENC - Provão, 1996). Resistência da comunidade } \\
\text { acadêmica à cultura de planejamento e avaliação ainda incipiente }\end{array}$ \\
\hline $\begin{array}{l}\text { Aprovação do Plano } \\
\text { Nacional de Educação }\end{array}$ & Lei 10.172 de 9 de janeiro de 2001 . \\
\hline $\begin{array}{l}11^{\mathrm{a}} \text { FASE } \\
\text { Criação do SINAES }\end{array}$ & $\begin{array}{l}\text { Instituído pela LEI 10.861/2004 (LEI ORDINÁRIA) 14/04/2004. Avanço na } \\
\text { cultura de planejamento e avaliação. A avaliação tem caráter formativo, } \\
\text { regulatório e diagnóstico visando a melhoria contínua da qualidade da } \\
\text { educação. }\end{array}$ \\
\hline $\begin{array}{l}12^{\circ} \text { FASE } \\
\text { Reestruturação do Plano de } \\
\text { Carreira dos Cargos } \\
\text { Técnicos Administrativos } \\
\text { em Educação }\end{array}$ & $\begin{array}{l}\text { Por meio da Lei } 11.095 \text {, de } 12 \text { de janeiro de } 2005 \text {, publicada no Diário Oficial } \\
\text { da União, o plano de carreira tem a função de reordenar e reagrupar os cargos } \\
\text { dos servidores. Além disso, a lei incorpora duas gratificações ao vencimento } \\
\text { básico dos funcionários, a Gratificação Temporária (GT) e a Gratificação } \\
\text { Específica de Apoio Técnico-Administrativo (GEAT). }\end{array}$ \\
\hline Criação do Prouni & $\begin{array}{l}\text { Lei } 11.096 \text { de } 13 \text { de janeiro de } 2005 \text { - institui o Programa Universidade para } \\
\text { Todos (PROUNI) que oferece bolsas de estudos em instituições de educação } \\
\text { superior privadas, em cursos de graduação e sequenciais de formação } \\
\text { específica, a estudantes brasileiros, sem diploma de nível superior. }\end{array}$ \\
\hline Criação do Reuni & $\begin{array}{l}\text { Decreto 6.096de } 24 \text { de abril de } 2007 \text { - Institui o Programa de Apoio a Planos } \\
\text { de Reestruturação e Expansão das Universidades Federais - REUNI. }\end{array}$ \\
\hline $\begin{array}{c}13^{\circ} \mathrm{FASE} \\
\text { Criação de Normas de } \\
\text { certificação sob o prisma da } \\
\text { Sustentabilidade }\end{array}$ & $\begin{array}{l}\text { ISO } 14001 \text { - Gestão do Meio Ambiente; ISO } 9001 \text { - Gestão da } \\
\text { qualidade;OHSAS } 18001 \text { - Saúde e segurança ocupacional; SA } 8000 \text { - } \\
\text { Responsabilidade Social; ISO } 26000 \text { - Responsabilidade Social. }\end{array}$ \\
\hline Criação do PNAES & $\begin{array}{l}\text { Decreto } 7.234 \text { de } 19 \text { de Julho de } 2010 \text { - Dispõe sobre o Plano Nacional de } \\
\text { Assistência Estudantil }\end{array}$ \\
\hline $\begin{array}{l}14^{\circ} \text { FASE } \\
\text { Plano Nacional de } \\
\text { Educação }\end{array}$ & $\begin{array}{l}\text { Criação do Plano Nacional de Educação para o Decênio de } 2011 \text { a } 2020 \\
\text { estabelecendo novas diretrizes e metas para o desenvolvimento sustentável; }\end{array}$ \\
\hline $\begin{array}{l}15^{\circ} \mathrm{FASE} \\
\text { Diretrizes Curriculares para } \\
\text { Educação }\end{array}$ & $\begin{array}{l}\text { O Presidente do CNE em conformidade com o disposto na Lei no } 9.394 \text {, de } 20 \\
\text { de dezembro de } 1996 \text {, e com fundamento no parecer CNE/CP n }{ }^{\circ} 14 / 2012 \text {, } \\
\text { publicado no DOU de } 15 \text { de junho de } 2012 \text {, aprova as Diretrizes Curriculares } \\
\text { Nacionais para Educação Ambiental }\end{array}$ \\
\hline Lei das Cotas (2012) & $\begin{array}{l}\text { Lei } 12.711 \text { de agosto de } 2012 \text { regulamentada pelo decreto } 7.824 / 12 \text { - garante } \\
\text { a reserva de } 50 \% \text { das matrículas por curso e turno para estudantes que } \\
\text { estudaram ensino médio em escolas públicas. }\end{array}$ \\
\hline \multicolumn{2}{|l|}{ VISÀO DE FUTURO } \\
\hline $\begin{array}{l}\text { ANÁLISE DO SISTEMA } \\
\text { AUTOPOIÉTICO }\end{array}$ & $\begin{array}{l}\text { Função de Memória auto-referente } \\
\text { organizacionalmente fechada }\end{array}$ \\
\hline
\end{tabular}




\begin{tabular}{|c|c|c|}
\hline & $\begin{array}{l}\text { Ima } \\
\text { ada da } \\
\text { isitivo. }\end{array}$ & $\begin{array}{l}\text { Adoção de modelos de } \\
\text { planejamento e avaliação } \\
\text { inovadores, assim como novas } \\
\text { abordagens }\end{array}$ \\
\hline \multicolumn{3}{|c|}{$\begin{array}{l}\text { Análise geral: identidade atual e perspectivas futuras } \\
\text { - Ainda é hegemônico um padrão recursivo de que a educação superior é para uma elite privilegiada; } \\
\text { - As IES públicas ainda são o local de estudo para quem cursou o ensino médio em colégios particulares; } \\
\text {-O perfil desejado para o egresso integra competências específicas e comportamentais, as quais se } \\
\text { destacam a ética e responsabilidade social. } \\
\text { - Neste contexto, destacam-se as concepções do Sistema Nacional de Avaliação da Educação Superior } \\
\text { (SINAES), as iniciativas estratégicas governamentais visando à inclusão social, tais como: PROUNI, } \\
\text { Sistema de vagas por cotas nas universidades, REUNI, entre outras. } \\
\text { - A inserção da Sustentabilidade nas políticas e estratégias da educação superior para o ensino, pesquisa, } \\
\text { extensão e gestão; } \\
\text { - Novos modelos de administração da educação superior, pautado na sustentabilidade com continuidade e } \\
\text { responsabilidade social das políticas e estratégias de longo prazo. } \\
\text { - Gradativamente está sendo implementado um novo paradigma, que integra de forma dual e } \\
\text { complementar, metas e resultados à dimensão humana. }\end{array}$} \\
\hline
\end{tabular}

Quadro 2 Identidade Autopoiética do Sistema de Educação Superior no Brasil Fonte: Elaborado pelos autores (2013)

Diante da relação dos marcos histórico e legal sobre a Educação Superior no Brasil percebe-se que a identidade autopoiética moldou-se ao longo do tempo sob a influência das políticas públicas instituídas pelo governo Estado, portanto, inserem-se neste aparato, momentos históricos que subsidiaram o governo no âmbito nacional, como: a república; regime militar; e democracia. Além disso, podem-se considerar as influências advindas das transformações no cenário macroeconômico e social, como capitalismo, globalização e revolução da informação, que provocaram mudanças de paradigmas em diversos setores.

Segundo dados do INEP (2012) apresenta que a educação superior no Brasil teve inúmeros acontecimentos marcantes, obteve-se seu início em Escolas Isoladas Profissionalizantes, posteriormente em escolas com justaposição de cursos superiores em 1968, reforma universitária e inserção da Constituição Federal em 1988, a expansão e regularização do ensino. Em 1996 culminaram com a aprovação da nova Lei de Diretrizes e Bases da Educação - LDB, tendo como principais destaques a diversificação institucional, a revogação da universidade como modelo, a dissociação do ensino e pesquisa, a flexibilização e institucionalização da EAD - Educação à Distância. Na década de 2000, em especial no ano de 2001, as novas diretrizes curriculares nacionais dos cursos de graduação em 2002, e as novas diretrizes dos cursos superiores de tecnologia. Nesta fase a educação superior passou por um processo de qualificação no ensino, tendo como um dos principais destaque a criação dos SINAES no ano de 2004 (INEP, 2012). 


\section{SUSTENTABILIDADE DAS POLÍTICAS E ESTRATÉGIAS PARA A EDUCAÇ̃̃O SUPERIOR NO BRASIL: UMA ANÁLISE SOB A ÓTICA DA TEORIA DOS SISTEMAS AUTOPOIÉTICOS DOI: http://dx.doi.org/10.5007/1983-4535.2015v8n2p153}

Com base no Quadro 2 da Identidade Autopoiética do Sistema de Educação Superior no Brasil, verifica-se que a evolução de sua trajetória, ao longo do tempo, tendo em vista a incorporação de diversas concepções ideológicas, na medida em que estabeleciam-se políticas públicas pertinentes à Educação Superior, geralmente estabelecidas por diretrizes de órgãos internacionais como a ONU, entre outros. Como visão de futuro da modelagem da identidade autopoiética da Educação Superior, pode-se relacionar a preocupação com a Sustentabilidade e Responsabilidade Social. Cabe expressar que o uso de ações e práticas, sob o enfoque da educação, meio ambiente e sustentabilidade são fundamentais para as diretrizes e processos, como a busca de compras sustentáveis em nível institucional, adoção de medidas legais que possibilitem a inclusão de pessoas com deficiência nas universidades, assim como demais grupos considerados vulneráveis como índios, negros e população de baixa renda.

Desta forma, percebe-se uma ruptura do paradigma elitista, que perdurou por longo período em sua trajetória. Na busca de mudanças do panorama, muitas ações e diretrizes estão sendo impostas pelo Estado, buscando melhorias e a inserção de políticas de controle, fomento e inclusão novas estratégias. Cabe salienta, que muitas ações que devem ser readaptadas apesar dos avanços, pois as IFES, que são instituições norteadoras do ensino brasileiro, que representam a atual estrutura do governo e a administração pública indireta, possuem prerrogativa de gestão, que a sua estrutura descentralizada garante ou deveria garantir a autonomia universitária, nos aspectos que tange à gestão administrativa, financeira e orçamentária. Nesta atual conjuntura de Reestruturação e Expansão das Universidades Federais - REUNI as Universidades têm o grande desafio de criar mecanismos para realizar a gestão.

Um dos avanços promissores por parte do Governo Federal deve-se em especial ao Ministério da Educação Brasileiro, que nos últimos anos com apoio de órgãos de fomento como a CAPES e o CNPQ, disponibilizam recursos para as IES realizarempesquisas na área de educação, em especial com foco na sustentabilidade. Uma das pesquisas que se destaca neste prisma, é o projeto Mapa Estratégico da Educação Superior (MEES), fundamentado em um sistema de gestão integrado: uma proposta metodológica para a operacionalização do Plano de Desenvolvimento Institucional, aprovado no edital Pró-Administração da CAPES.

O MEES é um sistema de gestão integrada para a administração da educação superior considerando as suas dimensões pedagógica, avaliativa, estratégica e informacional. Foi modelado para a operacionalização do Plano de Desenvolvimento Institucional e instrumentos 


\section{SUSTENTABILIDADE DAS POLÍTICAS E ESTRATÉGIAS PARA A EDUCAÇ̃̃O SUPERIOR NO \\ BRASIL: UMA ANÁLISE SOB A ÓTICA DA TEORIA DOS SISTEMAS AUTOPOIÉTICOS \\ DOI: http://dx.doi.org/10.5007/1983-4535.2015v8n2p153}

articulados. Para a sua implementação foi desenvolvido o sistema informacional de gestão integrada do mapa estratégico da educação superior (SIGMEES), o qual se constitui de software de suporte.

O Brasil, em sua fase atual de desenvolvimento socioeconômico, deve enfrentar o desafio de educar sua população e formar recursos humanos altamente qualificados, para consolidar uma política de ciência, educação e tecnologia, comprometida com a permanente construção de bases científicas, tecnológicas e de inovação requeridas à sustentabilidade social, ambiental, econômica, política e cultural.

Quanto a Responsabilidade Social Bessant e Tidd (2009), é um conceito muito amplo, que se discute em várias áreas do conhecimento, pois é um tema novo que começou a ser implementado nas organizações a partir do desenvolvimento sustentável e principalmente, de exigências impostas por normativas, regras de instituições, planejamento, participações de orgãos ativos em avaliações, e por livre interesse por parte dos gestores, em realizar ações sustentáveis de forma responsável.As iniciativas quanto à promoção da inclusão de pessoas com deficiência no âmbito da educação superior fazem parte da perspectiva sobre a responsabilidade social, segundo dados do Censo da Educação Superior do ano de 2011 mostram que em um contexto de 6.739 .689 de estudantes matriculados, 23.250 apresentam algum tipo de necessidade especial, o que representa, em percentual, apenas $0,35 \%$ do total de matrículas, subdivididos em: pessoas com deficiência (22160); pessoas com transtornos globais do desenvolvimento (137); e pessoas com altas habilidades/superdotação (953). Conforme INEP (2013) o entendimento sobre a aplicabilidade das ações de inclusão das pessoas com deficiência na educação superior reside não apenas na promoção da acessibilidade, mas também implica em estabelecer condições de participação e aprendizagem a estes estudantes, colaborando para a manutenção de uma cultura institucional inclusiva.

Dessa forma, o Sistema Nacional de Avaliação da Educação Superior (SINAES) contempla a dimensão sobre responsabilidade social, na medida em que institui instrumentos de que contemplam a dimensão da acessibilidade para os processos de avaliação, reconhecimento e renovação do reconhecimento de cursos de graduação. Nesse sentido o papel dos avaliadores é observar a prática dos dispositivos legais que fomentam a inclusão das pessoas com deficiência no ambiente acadêmico, verificando a existência de ações que congregam o ensino, a pesquisa, e a extensão neste âmbito, incluindo a existência do núcleo de acessibilidade da IES (INEP, 2013). 


\section{CONSIDERAÇÕES FINAIS}

Tomando-se por base a modelagem conceitual para análise da evolução das políticas e estratégias da educação superior, apresentada na seção anterior, apresentam-se as algumas conclusões relatadas a seguir. No que se refere à evolução, pode-se verificar que o Sistema de Educação Superior Brasileiro ocorreu de forma tardia, as Universidades passaram por um amplo processo regulatório, vários acontecimentos marcantes, em que cursos de Direito, Engenharia e Medicina dominaram o ambiente por longas décadas. A partir da década de 1980, verificou-se que o ensino entrou em pauta governamental, principalmente as regiões sudeste e centro do país tornaram-se as primeiras regiões com maior número de faculdades e escolas.

A partir da década de 1990 o ensino foi disseminado de forma planejada, para as demais regiões, com apoio do governo foram criadas inúmeras Universidades Federais, mais recentemente foram instituídos os Institutos Tecnológicos, bem como as legislações, sistemas como os SINAES, Plano Nacional de Educação, dentre outros que estão sendo documentos norteadores para as politicas e diretrizes para a educação superior brasileira.

Cabe salientar também que o sistema educacional sob a ótica da Sustentabilidade, em especial a Educação para Sustentabilidade, está em processo evolutivo, pois nos últimos cinco anos em especial, o Brasil tem sido um forte aliado da ONU para o fortalecimento de estratégias para a Sustentabilidade. Como resultado da Rio +20 , obteve-se diretrizes para o ensino, com enfoque de recomendações para a sustentabilidade, fazendo parte das grades curriculares de cursos de graduação.

Por fim ressalta-se que o reconhecimento das funções de memória organizacionalmente fechada e aberta cognitivamente com o ambiente, permite criar uma consciência estratégica, de modo a atenuar os padrões comportamentais reativos e incentivar a pró-atividade no sistema educacional brasileiro. Neste contexto podemos vislumbrar o desenvolvimento de planos estratégicos de longo prazo para até 20 anos, que visam o alinhamento da missão e visão da educação superior brasileira aos desejos e necessidades da comunidade acadêmica e sociedade.

Cabe expressar que este estudo trouxe importantes contribuições para a compreensão do processo de evolutivo da Educação Superior Brasileira, por meio do arcabouço teórico apresentado pode-se observar a importância dos sistemas adaptativos para as organizações, como as universidades foram criadas e suas relações com o governo. Outra contribuição 
importante foi à possibilidade que se vislumbrou de observar a teoria do sistema adaptativo autopoiese, como a lente norteadora do estudo, que contribuiu a elaboração de um quadro dos principais macros e acontecimentos da educação superior no país.

\section{REFERÊNCIAS}

ALVES, N. B.. (2013). A consciência ambiental dos jovens: uma pesquisa com estudantes de nível médio técnico e superior tecnológico. Dissertação 93 f. (dissertação de mestrado) UFRGS/RS, Porto Alegre/RS.

BARBIERI, J. C.. (2012). Educação ambiental e gestão ambiental na formação de um administrador: uma visão do quadro regulatório. São Paulo: Ottoni.

BEN-ELI, M. U. 92012) Sustentabilidade: os cinco princípios fundamentais. Recuperado em: $<$ http://www.sustainabilitylabs.org/page/sustainability-five-core-principles $>2006$.

Recuperado em: Nov.

BESSANT, J.; TIDD, J.. (2009). Inovação e empreendedorismo. Porto Alegre: Bookman.

COLOMBO, S. S; RODRIGUES, G. M.. (2011). Desafios da gestão universitária contemporânea. Porto Alegre: Artmed.

CORRÊA, A. C.; CUNHA, C.; SUTILLI, V.. (2003). The new paradigms of the science and their implications in the evolution and revolution of the knowledge. In:

2THINTERNATIONAL CONGRESS OF LOGIC, METHODOLOGY AND PHILOSOPHY OF SCIENCE, 2003. Oviedo. Anais...Oviedo: DLMPS - IUHPS.

CUNHA, I. M.. (2007). Reflexões e práticas em pedagogia universitária. Papirus: Campinas.

ELKINGTON, J.. (1997). Cannibals with Forks: the Triple Bottom Line of 21st Century Business. Oxford: Capstone Publishing.

ESTEVES, S. A. P.. (2009). Verdades Portáteis. Dilemas, desafios conceituais e limites da sustentabilidade no plano organizacional. Tese $245 \mathrm{f}$. (Tese de doutorado em Administração) Federação Getúlio Vargas - FGV. São Paulo.

FEAR, J. R.. (2001). Thinking historically about organizational learning. In M. Dierkes, A. Berthoin Antal, J. Child, \& I. Nonaka (Orgs.), The handbook of organizational learning and knowledge (pp.162-191). Oxford: Oxford University Press.

GORNEV, G.P.. (1997). A questão da criatividade na perspectiva da teoria de sistemas autopoiéticos, Kybernetes, v. 01. Iss 26: 6/7, (p.738-750).

HAIR, J. JR. Et al.. (2005) Fundamentos de métodos de pesquisa em administração. Porto Alegre: Bookman. 
HEDBERG, B.; WOLFF, R.. (2001). Organizing, Learning, and Strategizing: from construction to discovery. In: DIERKES, M. et al. Organizational learning \& knowledge, New York: Oxford.

INSTITUTO NACIONAL DE ESTUDOS E PESQUISAS EDUCACIONAIS ANÍSIO TEIXEIRA (INEP).. (2011). Sistema Nacional da Avaliação da Educação Superior: da concepção à regulamentação. ( $4^{\mathrm{a}}$ ed.) Brasília.

INSTITUTO NACIONAL DE ESTUDOS E PESQUISAS EDUCACIONAIS ANÍSIO TEIXEIRA (INEP).. (2012). Histórico da educação superior no pais. Recuperado em $<$ pos.brazcubas.br/moodle/file.php/.../Sistema_de_Educacao_Superior.ppt $>$ Recuperado em agosto.

INSTITUTO NACIONAL DE ESTUDOS E PESQUISAS EDUCACIONAIS ANÍSIO TEIXEIRA - INEP.. (2012). Planejamento Educacional. Recuperado em

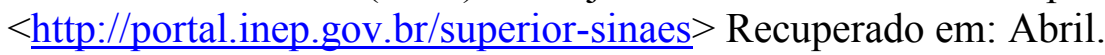

INSTITUTO NACIONAL DE ESTUDOS E PESQUISAS EDUCACIONAIS ANÍSIO TEIXEIRA (INEP), Ministério da Educação (MEC). (2012). Censo da educação superior: 2010 - resumo técnico. - Brasília: Instituto Nacional de Estudos e Pesquisas Educacionais Anísio Teixeira. 85 p. tab. ISBN: 978-85-7863-018-8.

JOHANNESSEN, J. B.. (1998). Coordination. In Press. Oxford: Oxford University Press.

MAIULA, M. (2000). The senses and memory of firm implications of autopoiesis theory for knowledge management. Journal of Knowledge Management. v. 4. n. 2. pp. 157-161. MCB University Press. Recuperado em http://www.emerald-library.com.

MATURANA, H; VARELA, F. J.. (1997). De máquinas e seres vivos. autopoiese - a organização do vivo. ( $3^{\mathrm{a}}$ ed.) Artes Médicas: Porto Alegre.

MINTZBERG, H.. (1993). The Design School: Reconsidering The Basic Premises Of Strategic management. Strategic Management Journal, v. 11, n. 3, p. 171-195.

MORGAN, G.. (1996). Imagens da organização. São Paulo: Atlas.

NETO, L.M; GARRIDO, P. O.; JUSTEN, C. E.. (2011). Desenvolvendo o aprendizado em gestão social: proposta pedagógica de fomento às incubadoras sociais. Cadernos EBAPE.BR. FGV.

Plano Nacional de Educação - PNE..(2011). Por um plano nacional de educação (2011-2020) como politica de estado. Anped. Rio de Janeiro.

RICHARDSON, R., J. et al..(1999). Pesquisa Social: métodos e técnicas. 2.ed. São Paulo: Atlas.

SAVIANI, D. A.. (2010). A expansão do Ensino Superior no Brasil: Revista Mudanças e Continuidades. Poíesis Pedagógica - V.8, N.2 ago/dez. pp.4-17. 
SCHUCH JR., V. F.. (2005). A estruturação da universidade em questão: o caso da UFSM. Revista RBAE. V.11 n.2 p.1-113 Brasília jul/dez.

SHRIVASTAVA, P.. (2010). Pedagogy of Passion for Sustainability. Journal Academy of Management Learning \& Education. V. 9, n. 3, p. 443-455.

SPELLER, P.. (2012). O papel da educação superior nos países em desenvolvimento: o caso do Brasil. Anais do Fórum da Gestão do Ensino Superior nos Países e Regiões de Língua Portuguesa - FORGES. Recuperado em

$<$ aforges.org/conferencia2/docs.../Paineis.../Speller_Paulo\%20(BR).pdf> .

TERMIGNONI, L. D. F. (2012). Framework de sustentabilidade para instituições de ensino superior comunitárias. Dissertação 215 f. (Dissertação de Mestrado) PUC/RS. Porto Alegre/RS.

WCED - Comissão Mundial sobre Meio Ambiente e Desenvolvimento.. (2012). Nosso Futuro Comum, 1987. Recuperado em <http://www.un-documents.net/wced-ocf.htm $>$.Recuperado em: Novembro .

ZANDAVALLI, C. B. (2009). Avaliação da Educação Superior no Brasil: os antecedentes históricos do SINAES. Avaliação, Campinas; Sorocaba, SP, v. 14, n. 2, p. 267-290, jul.

ZITZKE, V. A.. (2002). Educação ambiental e eco desenvolvimento. Revista Eletrônica do Mestrado em Educação Ambiental. Vol 9, p.175-188, jul./dez. 2002. Porto Alegre/RS. 